\title{
Stress time-dependently influences the acquisition and retrieval of unrelated information by producing a memory of its own
}

\author{
Chelsea E. Cadle and Phillip R. Zoladz* \\ Department of Psychology, Sociology, and Criminal Justice, Ohio Northern University, Ada, OH, USA
}

Stress induces several temporally guided "waves" of psychobiological responses that differentially influence learning and memory. One way to understand how the temporal dynamics of stress influence these cognitive processes is to consider stress, itself, as a learning experience that influences additional learning and memory. Indeed, research has shown that stress results in electrophysiological and biochemical activity that is remarkably similar to the activity observed as a result of learning. In this review, we will present the idea that when a stressful episode immediately precedes or follows learning, such learning is enhanced because the learned information becomes a part of the stress context and is tagged by the emotional memory being formed. In contrast, when a stressful episode is temporally separated from learning or is experienced prior to retrieval, such learning or memory is impaired because the learning or memory is experienced outside the context of the stress episode or subsequent to a saturation of synaptic plasticity, which renders the retrieval of information improbable. The temporal dynamics of emotional memory formation, along with the neurobiological correlates of the stress response, are discussed to support these hypotheses.

Keywords: stress, long-term potentiation (LTP), hippocampus, amygdala, metaplasticity

\section{What is Stress?}

Stress is experienced during situations that pose a threat to an organism and leads to the activation of two major physiological systems, the sympathetic nervous system (SNS) and the hypothalamuspituitary-adrenal (HPA) axis. SNS activation allows for the immediate fight-or-flight response through rapid release of epinephrine (EPI) and norepinephrine (NE) from the adrenal medulla (Gunnar and Quevedo, 2007). Activation of the HPA axis, on the other hand, leads to a slower response, eventually resulting in the release of corticosteroids from the adrenal cortex (de Kloet et al., 1999; Joels, 2001).

Stress response neurochemicals exert a profound effect on learning and memory by influencing cognitive brain areas, such as the hippocampus, prefrontal cortex (PFC), and amygdala. Both the hippocampus, which is crucial for the formation of declarative and spatial memories (Moser and Moser, 1998; Kaut and Bunsey, 2001; Broadbent et al., 2004; Eichenbaum, 2004; Squire et al., 2004; Broadbent et al., 2006), and the PFC, which is responsible for working memory and higher-order cognitive function (Rowe et al., 2001; Bechara, 2005; Nebel et al., 2005; Muller and Knight, 2006), have a high density of corticosteroid receptors (McEwen et al., 1968, 1969; Mcewen et al., 1970; 
Diorio et al., 1993; McGaugh, 2004), making them highly susceptible to the effects of stress. The amygdala is primarily responsible for the processing of emotional information and serves to exacerbate the stress response by enhancing HPA axis activity (McGaugh, 2004; Roozendaal et al., 2009). Stress differentially impacts learning that is dependent on these brain areas, and when considering the different forms of stress-memory interactions, the most complex appears to be that of stress effects on hippocampus-dependent memory (Zoladz et al., 2014a), which will be the focus of this review.

\section{Type of stress}

Stress effects on learning and memory depend on the type of stressor that is employed. Intrinsic stress is a stressor that is intrinsic to, or a part of, the learning experience, and extrinsic stress is a stressor that is extrinsic to, or outside, the learning experience. In general, intrinsic stress (e.g., emotionally arousing words in a word list, colder water temperature in a Morris water maze) facilitates learning and memory (Sandi et al., 1997; Cahill and McGaugh, 1998). Extrinsic stress (e.g., exposing participants to a stressor and then having them learn a word list, shocking rats and subsequently testing their ability to navigate a maze) effects on learning and memory, on the other hand, are much more complex and can involve enhancement, impairment or no effects on cognition (Joels et al., 2006; Zoladz et al., 2011b, 2014a). In the present review, we will focus on the influence of extrinsic stress on learning and memory. During a stressful, or even traumatic, event (e.g., wartime combat, witnessing a crime), learning that occurs often results in a powerful memory for the stressor, although this may depend on what aspects (i.e., central or peripheral details) about the stressor are tested (see section below). Here, it is our goal to discuss how the physiological changes that occur during the stress impact learning and memory for events that occur subsequent to/prior to stress exposure.

\section{Stress Effects on Learning and Memory Depend on Stage}

Learning and memory can generally be divided into three major stages: encoding, consolidation and retrieval. Encoding involves the acquisition phase, during which information is initially learned. Consolidation is when the learned information is stored in order to be successfully retrieved (the third stage) at a later point in time. Most research, in both humans and rodents, has reported facilitative effects of post-learning stress or corticosteroid administration on long-term memory consolidation (Cahill et al., 2003; Beckner et al., 2006; Hui et al., 2006; Smeets et al., 2008; Preuss and Wolf, 2009) and deleterious effects of stress or corticosteroid administration on long-term memory retrieval (de Quervain et al., 1998; Buss et al., 2004; Kuhlmann et al., 2005a,b; Buchanan et al., 2006; Diamond et al., 2006; Buchanan and Tranel, 2008; Park et al., 2008; Smeets et al., 2008; Tollenaar et al., 2008). The effects of pre-learning stress or corticosteroid administration on encoding have been more inconsistent, with studies revealing long-term memory enhancements, impairments or no effects at all (Kim et al., 2001, 2005; Jelicic et al., 2004; Elzinga et al., 2005; Diamond et al., 2006; Payne et al., 2006, 2007; Nater et al., 2007; Park et al., 2008; Schwabe et al., 2008; Duncko et al., 2009; Zoladz et al., 2011a, 2013, 2014b). Importantly, because it is administered prior to encoding, prelearning stress can affect both the acquisition and storage of information; thus, researchers often assess short-term memory in such studies to infer what stage of information processing is being affected. A representative summary of the research studies that have examined stress effects on hippocampus-dependent learning and memory is illustrated in Table 1.

The effects of stress on different stages of learning and memory appear to depend on an interaction between corticosteroid and noradrenergic mechanisms in the amygdala and hippocampus. Inactivation or lesions of the basolateral amygdala (BLA), as well as systemic or intra-BLA/intra-hippocampus administration of $\beta$-adrenergic receptor antagonists, have been shown to prevent stress and corticosteroid effects on learning and memory (Kim et al., 2001; Roozendaal et al., 2003, 2004; Kim et al., 2005; Zoladz et al., 2011b). Additionally, the effects of stress are frequently selective for emotionally arousing (i.e., amygdalaactivating) information (Kuhlmann et al., 2005b; Buchanan et al., 2006; Smeets et al., 2008), emphasizing amygdala involvement in the effects. Another contributing factor to stress-memory interactions is the type of information affected. That is to say, stress often exerts differential effects on learning and memory for central and peripheral details. During stress or arousal, attention is narrowed (Easterbrook, 1959), which can hinder one's ability to subsequently learn or remember peripheral aspects of an event or scene. Thus, in some instances, stress can enhance one's memory for the gist, or central aspects, while impairing an individual's ability to recollect finer details (Kensinger, 2004). These findings resonate with additional work showing that stress sometimes facilitates memory for emotional, potentially more important, information, at the cost of memory for neutral, potentially less important, information (Payne et al., 2006, 2007).

\section{Theoretical Approaches to Stress Effects on Cognition}

Over the past several decades, numerous theories have been proposed to account for stress effects on learning and memory. Initially, researchers emphasized the deleterious effects of elevated corticosteroid levels on synaptic plasticity and related them to the effects of stress on learning (Joels and Vreugdenhil, 1998; Conrad et al., 1999). Glucocorticoid receptors (GRs), which have a lower affinity for corticosteroids than mineralocorticoid receptors (MRs), generally only become occupied when corticosteroid levels rise, such as during times of stress. The idea put forth was that moderate GR activity is optimal for cognitive processes, but too much GR activity, such as that which occurs following stress, has negative repercussions for 
TABLE 1 | Summary of the findings from studies examining acute stress effects on hippocampus-dependent learning and memory.

\begin{tabular}{|c|c|c|c|c|c|c|}
\hline Study & Stress & Stress Timing & $\begin{array}{l}\text { Stress } \\
\text { Duration }\end{array}$ & Task & Effects & Caveats \\
\hline Beckner et al. (2006) & $\begin{array}{l}\text { Post-learning TSST } \\
\text { Pre-retrieval TSST }\end{array}$ & 30-min delay & $10-15 \min$ & Film & $\begin{array}{l}\uparrow \mathrm{LTM} \\
---\mathrm{LTM}\end{array}$ & \\
\hline $\begin{array}{l}\text { Buchanan and Tranel } \\
\text { (2008) }\end{array}$ & Pre-retrieval TSST & 10-min delay & $20 \mathrm{~min}$ & Picture learning & $\downarrow$ LTM & $\begin{array}{l}\text { Impairment in cortisol } \\
\text { responders }\end{array}$ \\
\hline Buchanan et al. (2006) & $\begin{array}{l}\text { Post-learning/pre- } \\
\text { retrieval } \\
\text { CPT }\end{array}$ & $\begin{array}{l}\text { 1-h post-learning, } \\
\text { 10-min pre-retrieval }\end{array}$ & $\sim 3 \min$ & Word learning & $\downarrow$ LTM & $\begin{array}{l}\text { Impairment in cortisol } \\
\text { responders }\end{array}$ \\
\hline Cahill et al. (2003) & Post-learning CPT & Immediately & $\sim 3 \mathrm{~min}$ & Picture learning & $\uparrow \mathrm{LTM}$ & \\
\hline Campbell et al. (2008)* & $\begin{array}{l}\text { Pre-retrieval cat } \\
\text { exposure }\end{array}$ & $\begin{array}{l}\text { Immediately or 60-min } \\
\text { delay }\end{array}$ & $\sim 20-30 \mathrm{~min}$ & Water maze & $\downarrow$ STM & \\
\hline Conboy et al. (2009)* & $\begin{array}{l}\text { Pre-retrieval/post- } \\
\text { learning cat } \\
\text { exposure }\end{array}$ & Immediately & $30 \mathrm{~min}$ & Water maze & $\downarrow$ STM & \\
\hline Conrad et al. (2004)* & $\begin{array}{l}\text { Pre-learning restraint } \\
\text { stress }\end{array}$ & 1-h delay & $1 \mathrm{~h}$ & Y-maze & $\downarrow$ STM & Only males impaired \\
\hline de Quervain et al. (1998)* & Pre-retrieval foot shock & 30-min delay & $\sim 1 \min$ & Water maze & $\downarrow$ LTM & \\
\hline Diamond et al. (1996)* & $\begin{array}{l}\text { Pre-retrieval/post- } \\
\text { learning novelty } \\
\text { stress }\end{array}$ & Immediately & $4 \mathrm{~h}$ & $\begin{array}{l}\text { Radial arm } \\
\text { maze }\end{array}$ & $\downarrow$ STM & $\begin{array}{l}\text { Reference memory } \\
\text { unaffected }\end{array}$ \\
\hline Diamond et al. (1999)* & $\begin{array}{l}\text { Pre-retrieval/post- } \\
\text { learning cat } \\
\text { exposure }\end{array}$ & Immediately & $30 \mathrm{~min}$ & Water maze & $\downarrow$ STM & Easy task unaffected \\
\hline Diamond et al. (2006)* & $\begin{array}{l}\text { Pre-learning and } \\
\text { pre-retrieval cat } \\
\text { exposure }\end{array}$ & Immediately & $30 \mathrm{~min}$ & Water maze & $\downarrow$ LTM & \\
\hline Diamond et al. (2007)* & $\begin{array}{l}\text { Pre-learning cat } \\
\text { exposure }\end{array}$ & $\begin{array}{l}\text { Immediately } \\
30 \text { min delay }\end{array}$ & $2 \min$ & Water maze & $\begin{array}{l}\uparrow \mathrm{LTM} \\
---\mathrm{LTM}\end{array}$ & \\
\hline Elzinga et al. (2005) & $\begin{array}{l}\text { Pre-learning cognitive } \\
\text { stress }\end{array}$ & 10-15-min delay & $20 \mathrm{~min}$ & $\begin{array}{l}\text { Word list, } \\
\text { paragraph, } \\
\text { spatial }\end{array}$ & $\downarrow$ LTM & \\
\hline Felmingham et al. (2012) & Post-learning CPT & Immediately & $3 \min$ & Picture learning & $\uparrow \mathrm{LTM}$ & $\begin{array}{l}\text { Only for emotional info } \\
\text { in females }\end{array}$ \\
\hline Jelicic et al. (2004) & Pre-learning TSST & Immediately & $20 \mathrm{~min}$ & Word learning & $\begin{array}{l}\downarrow \text { STM } \\
\uparrow \text { STM }\end{array}$ & $\begin{array}{l}\text { Impaired neutral, } \\
\text { enhanced emotional }\end{array}$ \\
\hline Kim et al. (2005)* & $\begin{array}{l}\text { Pre-learning } \\
\text { restraint + tailshock }\end{array}$ & Delayed & $60 \min$ & Water maze & $\downarrow$ LTM & \\
\hline Kim et al. (2001)* & $\begin{array}{l}\text { Pre-learning } \\
\text { restraint + tailshock }\end{array}$ & 30-60 min delay & $60 \min$ & Water maze & $\downarrow$ LTM & \\
\hline Kuhlmann et al. (2005b) & Pre-retrieval TSST & 10-min delay & $\sim 10 \min$ & Word learning & $\downarrow$ LTM & $\begin{array}{l}\text { Only emotional words } \\
\text { impaired }\end{array}$ \\
\hline Li et al. (2013) & $\begin{array}{l}\text { Post-learning/pre- } \\
\text { retrieval } \\
\text { TSST }\end{array}$ & $\begin{array}{l}\text { 1-h post-learning, } \\
\text { immediately } \\
\text { pre-retrieval }\end{array}$ & $\sim 15 \min$ & Face learning & $\downarrow$ STM & \\
\hline $\begin{array}{l}\text { Mccullough and Yonelinas } \\
\text { (2013) }\end{array}$ & Post-learning CPT & 20-min delay & $3 \mathrm{~min}$ & Picture learning & $\uparrow$ STM & \\
\hline Nater et al. (2007) & Pre-learning TSST & Immediately & $15-20 \mathrm{~min}$ & Word learning & $\uparrow$ STM & $\begin{array}{l}\text { Only enhanced cortisol } \\
\text { responders }\end{array}$ \\
\hline Park et al. (2006)* & $\begin{array}{l}\text { Pre-retrieval/post- } \\
\text { learning cat } \\
\text { exposure }\end{array}$ & Immediately & $30 \mathrm{~min}$ & Water maze & $\downarrow$ LTM & \\
\hline Park et al. (2008)* & $\begin{array}{l}\text { Pre-learning and } \\
\text { pre-retrieval cat } \\
\text { exposure }\end{array}$ & Immediately & $30 \mathrm{~min}$ & Water maze & $\downarrow$ LTM & \\
\hline Payne et al. (2007) & Pre-learning TSST & Immediately & $20 \mathrm{~min}$ & Picture learning & $\begin{array}{l}\uparrow \mathrm{LTM} \\
\downarrow \mathrm{LTM}\end{array}$ & $\begin{array}{l}\text { Enhanced emotional, } \\
\text { impaired neutral }\end{array}$ \\
\hline Payne et al. (2006) & Pre-learning TSST & A few minutes delay & $20 \min$ & Picture learning & $\downarrow$ LTM & Only impaired neutral \\
\hline Payne et al. (2002) & Pre-learning TSST & Immediately & $10-15 \mathrm{~min}$ & $\begin{array}{l}\text { False memory } \\
\text { production }\end{array}$ & $\begin{array}{l}\uparrow \text { false } \\
\text { memory }\end{array}$ & \\
\hline
\end{tabular}


TABLE 1 | Continued

\begin{tabular}{|c|c|c|c|c|c|c|}
\hline Study & Stress & Stress Timing & $\begin{array}{l}\text { Stress } \\
\text { Duration }\end{array}$ & Task & Effects & Caveats \\
\hline Preuss and Wolf (2009) & Post-learning TSST & 5-min delay & $15 \mathrm{~min}$ & Word learning & $\uparrow \mathrm{LTM}$ & Only enhanced neutral \\
\hline Schoofs and Wolf (2009) & Pre-retrieval TSST & 10-min delay & $15 \min$ & Word learning & ---- LTM & $\begin{array}{l}\text { Only tested women in } \\
\text { luteal phase }\end{array}$ \\
\hline Schwabe and Wolf (2014) & Pre-retrieval CPT & $\begin{array}{l}\text { Immediately } \\
\text { 25-min delay } \\
\text { 90-min delay }\end{array}$ & $3 \mathrm{~min}$ & Word learning & $\begin{array}{l}--- \text { LTM } \\
\downarrow \text { LTM } \\
\downarrow \text { LTM }\end{array}$ & \\
\hline Smeets (2011) & Pre-retrieval CPT & 15-min delay & $3 \min$ & Word learning & $\downarrow$ LTM & \\
\hline Smeets et al. (2008) & $\begin{array}{l}\text { Pre-learning CPT } \\
\text { Post-learning CPT } \\
\text { Pre-retrieval CPT }\end{array}$ & $\begin{array}{l}\text { 5-min delay } \\
\text { 5-min delay } \\
\text { 8-min delay }\end{array}$ & $3 \mathrm{~min}$ & Word learning & $\begin{array}{l}--- \text { LTM } \\
\uparrow \text { LTM } \\
\downarrow \text { LTM }\end{array}$ & \\
\hline Smeets et al. (2009) & $\begin{array}{l}\text { Pre-learning TSST } \\
\text { Pre-learning TSST } \\
\text { Post-learning TSST }\end{array}$ & $\begin{array}{l}5 \text { min delay } \\
2 \text { h delay } \\
1 \text { h delay }\end{array}$ & $20 \mathrm{~min}$ & $\begin{array}{l}\text { Stressor-related } \\
\text { and stress- } \\
\text { unrelated } \\
\text { words }\end{array}$ & $\begin{array}{l}\uparrow \text { LTM } \\
\uparrow \text { LTM } \\
--- \text { LTM }\end{array}$ & $\begin{array}{l}\text { Only stress-related } \\
\text { words affected }\end{array}$ \\
\hline Woodson et al. (2003)* & $\begin{array}{l}\text { Post-learning/pre- } \\
\text { retrieval cat } \\
\text { exposure }\end{array}$ & Immediately & 30-45 min & Water maze & $\downarrow$ STM & \\
\hline Zoladz et al. (2014a) & Pre-retrieval CPT & Immediately & $3 \mathrm{~min}$ & Word learning & $\begin{array}{l}\uparrow \text { LTM } \\
\downarrow \text { LTM }\end{array}$ & $\begin{array}{l}\text { Enhanced male cortisol } \\
\text { responders; impaired } \\
\text { male cortisol } \\
\text { non-responders }\end{array}$ \\
\hline Zoladz et al. (2011a) & Pre-learning CPT & $\begin{array}{l}\text { Immediately } \\
\text { 30-min delay }\end{array}$ & $3 \mathrm{~min}$ & $\begin{array}{l}\text { Word list } \\
\text { learning }\end{array}$ & $\begin{array}{l}\uparrow \text { LTM } \\
\downarrow \text { LTM }\end{array}$ & $\begin{array}{l}\text { Only emotional words } \\
\text { affected }\end{array}$ \\
\hline Zoladz et al. (2013) & Pre-learning CPT & 30-min delay & $3 \mathrm{~min}$ & $\begin{array}{l}\text { Word list } \\
\text { learning }\end{array}$ & $\downarrow$ LTM & $\begin{array}{l}\text { Only impaired in male } \\
\text { cortisol responders }\end{array}$ \\
\hline Zoladz et al. (2010)* & $\begin{array}{l}\text { Post-learning/pre- } \\
\text { retrieval IA training or IA } \\
\text { retrieval }\end{array}$ & Immediately & $30 \mathrm{~min}$ & Water maze & $\downarrow$ STM & \\
\hline
\end{tabular}

CPT, cold pressor test; HR, heart rate; IA, inhibitory avoidance; LTM, long-term memory ( $\geq 24$ h); MAST, Maastricht Acute Stress Test; STM, short-term memory (<24 h); TSST, Trier Social Stress Test. In some cases, the CPT was the socially evaluated version (SECPT); rat studies are marked with an asterisk (*).

synaptic plasticity and, therefore, learning. Support for this idea came from studies reporting a curvilinear, U-shaped relationship between corticosteroids and hippocampal synaptic plasticity and learning (Diamond et al., 1992; Andreano and Cahill, 2006), as well as from research showing that extensive GR activity results in excessive calcium influx and negative gene-dependent effects on cellular function (Joels et al., 2003). Combined with work on chronic stress and corticosteroid-hippocampal volume relationships observed in humans with psychological disorders (Campbell et al., 2004; Zoladz and Diamond, 2013), a majority of the research led investigators to conclude that stress generally exerts deleterious effects on hippocampal structure and function.

Over time, a greater appreciation for the complexity of stress-memory interactions arose, as evidence accumulated suggesting that stress could enhance, impair or have no effect on hippocampus-dependent learning and synaptic plasticity. Researchers began showing that corticosteroids not only have 
delayed, gene-dependent, negative consequences on cellular activity, but can also exert rapid, non-genomic, facilitative effects (Orchinik et al., 1991; Karst et al., 2005). This led to much different theoretical approaches to how stress affects cognition, including an appreciation for the timing of the stress relative to learning or memory, the sex of the organism being investigated, and the type of learning and memory being assessed, to name a few (Joels et al., 2006; Diamond et al., 2007; Wolf, 2009; Joels et al., 2011; Schwabe et al., 2012). Diamond and colleagues, echoing prior theoretical views (Diamond et al., 1990; Shors and Thompson, 1992), put forth another idea - that stress might impair memory by producing a memory of its own (Diamond et al., 2004, 2005). Here, we have extended this view to consider how stress, as a memory formation process, time-dependently affects encoding, consolidation, and retrieval.

\section{Stress as a Learning Event}

For the past several decades, long-term potentiation (LTP) has been studied as a putative physiological mechanism underlying memory formation (Shors and Matzel, 1997; Kim and Yoon, 1998; Diamond et al., 2007; Joels and Krugers, 2007). LTP is a long-lasting enhancement of synaptic efficacy that results from high-frequency stimulation (HFS) of afferent fibers (Hebb, 1949; Marr, 1971; Lomo, 2003) and can be performed in vitro (in brain slices), in awake and behaving animals, or in anesthetized animals (Lynch, 2004). In vitro setups keep brain tissue functional via artificial cerebrospinal fluid and allow investigators to stimulate and record from populations of neurons. Setups in awake or anesthetized animals involve intracerebral implantation of stimulating and recording electrodes via stereotaxic surgery; these electrodes can subsequently be used to examine LTP induction. Successful memory formation for a learning event is believed to coincide with the strengthening of neural connections and a lasting pattern of altered synaptic weights. However, if multiple LTP-inducing events occur in close proximity, the limited number of available neurons may result in a "ruthless competition" for access to synaptic plasticity production and successful memory formation (Diamond et al., 2004, 2005). In other words, with limited resources, the brain would be forced to prioritize information that is more important.

In an effort to understand the dynamic nature of hippocampus-dependent memory formation, researchers have examined the influence of LTP induction on subsequent hippocampal synaptic plasticity and learning. Application of HFS to afferent fibers has been shown to produce widespread saturation of hippocampal synapses, and the long-lasting alteration of synaptic weights produced by this HFS can lead to an inhibition of subsequent LTP and hippocampus-dependent learning (Huang et al., 1992; Barnes et al., 1994; Moser and Moser, 1998, 1999; Otnaess et al., 1999). This activity-dependent modification of synaptic efficacy has been termed metaplasticity, corresponding to the notion that a prior change in synaptic plasticity can influence the direction and degree of subsequent changes in synaptic plasticity (Abraham and Bear, 1996).
Because we know that prior LTP induction can influence subsequent LTP induction, it stands to reason that the formation of one memory could influence subsequent memory formation. However, research has shown that this tends to occur only when a learning task produces widespread synaptic saturation (extensively reviewed in Diamond et al., 2004). Learning events that produce such a strong memory or change in synaptic plasticity are those that have a strong emotional component and elicit a significant stress response. Accordingly, research has revealed very similar molecular mechanisms underlying stressand LTP-induced changes in hippocampal function (see Huang et al., 2005 for a review). Some of these commonalities include increased early gene induction (Cole et al., 1989; Schreiber et al., 1991; Platenik et al., 2000), increased NMDA and AMPA receptor activity (Tocco et al., 1991, 1992; Kim et al., 1996; Brun et al., 2001), increased levels of neurotrophins [e.g., brain-derived neurotropic factor (BDNF; Gooney and Lynch, 2001; Marmigere et al., 2003)] and increased glutamate and intracellular calcium levels (Sapolsky, 1996; Abraham et al., 1998; Hossmann, 1999; Venero and Borrell, 1999; Joels, 2001; Takahashi et al., 2002; Joels et al., 2003; McEwen and Chattarji, 2004). Additional evidence for shared mechanisms between artificially induced LTP and stress-induced neuroplasticity is research indicating that NMDA receptor antagonists, which impair LTP induction, prevent the effects of stress on subsequent hippocampus-dependent learning and LTP (Kim et al., 1996; Park et al., 2004). In theory, the NMDA receptor antagonists block the stress-memory formation, which allows subsequent hippocampus-dependent learning and LTP to occur. Research has also shown that despite stress impairing subsequent learning and LTP induction, the memory for the stress-inducing event remains intact (Diamond et al., 2004; Zoladz et al., 2010). Together, these findings have provided support for the idea that stress induces an endogenous form of LTP that allows a memory of the stress experience to be formed. Although this is adaptive, because it allows an organism to remember the stress experience, in some cases it can also serve to impair subsequent cognitive processing.

\section{Stress Effects on Learning and Memory and the Important Role of Timing}

Knowing that stress exposure results in the activation of molecular mechanisms that are remarkably similar to those observed as a result of artificially induced synaptic plasticity, we might consider stress, itself, as a memory-producing event. Viewed in this light, stress, and the waves of psychobiological responses that result from such a learning event, can be expected to strongly influence the successful encoding, consolidation, and retrieval of unrelated information (i.e., information not related to the stressor).

Stress effects on the retrieval of previously learned information could be understood as the formation of one memory (i.e., the stress-memory) interfering with the retrieval of another memory. Similar to this line of reasoning, studies have shown that LTP can produce retrograde amnesia for previously learned 
information (McNaughton et al., 1986; Brun et al., 2001). In theory, the initial learning task (spatial learning in this case) leads to the potentiation of a small subset of synapses, and the preretrieval LTP leads to a complete saturation of synaptic nodes. The all-encompassing wave of plasticity that results from the LTP induction alters the pattern of synaptic weights throughout the hippocampus, resulting in an impaired ability to retrieve the previously formed memory. Consistent with these findings, and as described above, studies examining stress effects on retrieval have found that acute stress exposure that occurs before a memory test leads to impaired memory performance, while preserving the memory that has formed as a result of stress exposure (Diamond et al., 2004; Zoladz et al., 2010). In the referenced studies, rats trained in an inhibitory avoidance task that involved foot shock as an unconditioned stimulus (i.e., a stressor) exhibited impaired spatial memory retrieval, despite retaining the shock-induced fear memory that was formed in the inhibitory avoidance task. This effect was observed when the spatial learning and memory occurred on the same day or when they were separated by $24 \mathrm{~h}$. Importantly, the memory impairment may not result from complete elimination of the original memory. Instead, the stress-induced neuroplasticity may cause an impaired ability to activate the synapses required to retrieve the previously formed memory (Diamond et al., 2004).

As described above, post-learning stress almost always enhances long-term memory, but pre-learning stress effects on long-term memory have resulted in inconsistent findings. The timing of stress relative to learning has been shown to influence both types of effects. Studies in which learning or HFS of afferent fibers occurred immediately before or after stress exposure revealed a significant enhancement of longterm memory or an increase in the duration of hippocampal LTP (reviewed in Diamond et al., 2007). In the same way that stress exposure immediately after a learning event leads to a strong memory formation for both the stress event and unrelated learning event, acute stress exposure occurring immediately before an unrelated learning event typically facilitates memory formation for both events (note that the facilitation can be selective for emotional/neutral or central/peripheral information). Alternatively, when acute stress exposure is temporally separated from a prior or subsequent unrelated learning event, memory formation for that learning event is often impaired (pre-learning stress) or unaffected (postlearning stress).

Based on the seemingly time-dependent effects of stress on hippocampal function, Diamond et al. (2007) developed the temporal dynamics model of emotional memory processing. This model illustrates the biphasic modulation of hippocampal function by stress-induced amygdala activity and is described in Figure 1. The first phase encompasses a rapid enhancement of hippocampal plasticity resulting from stress-induced neurochemical interactions in the amygdala and hippocampus. Support for this phase comes from electrophysiological work showing that stimulation of the amygdala immediately prior to HFS in the hippocampus results in strengthened synaptic connections in the hippocampus (Akirav and Richter-Levin, 1999, 2002). Importantly, this amygdala-induced enhancement of hippocampal plasticity depends on both noradrenergic and corticosteroid mechanisms. During this phase, corticosteroids released as a result of stress would be expected to exert rapid, excitatory effects on hippocampal function as a result of nongenomic activity (Karst et al., 2005; Karst and Joels, 2005). The stress-induced facilitation of hippocampal function, however, is short lived and may last only minutes after onset of the stress experience. The second phase of the model represents a refractory period during which the acquisition of new information or LTP induction would be improbable. This refractory period is caused by the desensitization of glutamatergic receptors, which have been over-stimulated by stress-induced glutamate release, and delayed, gene-dependent activity of corticosteroids. Accordingly, in electrophysiological work, when amygdala stimulation and hippocampal HFS are separated in time, the resulting synaptic change is a suppression of hippocampal LTP. Thus, application of tetanic stimulation during the refractory period would likely fail to overcome the newly elevated threshold for LTP induction.

Consistent with the temporal dynamics model, Schwabe et al. (2012) proposed that the rapid stress-induced increase of catecholamine and non-genomic corticosteroid activity puts an organism in a 'memory formation mode', which results in enhanced memory production for a stressful event and information that is temporally proximal to such an event. However, as the stress continues and/or upon the initiation of gene-dependent corticosteroid activity, a 'memory storage mode' is induced, which impairs cognitive processes that could compete or interfere with the storage of information about the stress event. Both Diamond and Schwabe would likely agree that the temporal dynamics of memory processing subsequent to stress exposure is adaptive, despite the fact that it can result in enhancing $\underline{o r}$ deleterious effects on learning and memory. When a stressful experience occurs, it is beneficial to survival for an organism to form a strong memory of that event. Moreover, the suppression of subsequent cognitive processing or memory formation would also be advantageous because it allows the brain to focus on storing the stressrelated memory, without interference from competing cognitive processes.

The temporal dynamics model addresses the functionality of the hippocampus from stress onset to hours after stress exposure. This information can be extended to understand how stress, as a learning experience, influences additional unrelated learning experiences. We have summarized the research studies that have examined the effects of acute stress, administered at different time points, on hippocampus-dependent learning and memory in Table 1. Stress-induced facilitation or impairment of unrelated information will be largely determined by the convergence of information from the stress and learning experiences in "time" and "space" (Joels et al., 2006). Convergence of the experiences in "time" relates to the idea of stress and learning occurring in close temporal proximity, whereas the convergence in "space" refers to the two events sharing mutual brain circuits that overlap during the memory formation process. As such, stress will enhance memory when a learning event occurs in the same context as the stress event, or when the two events occur 
A

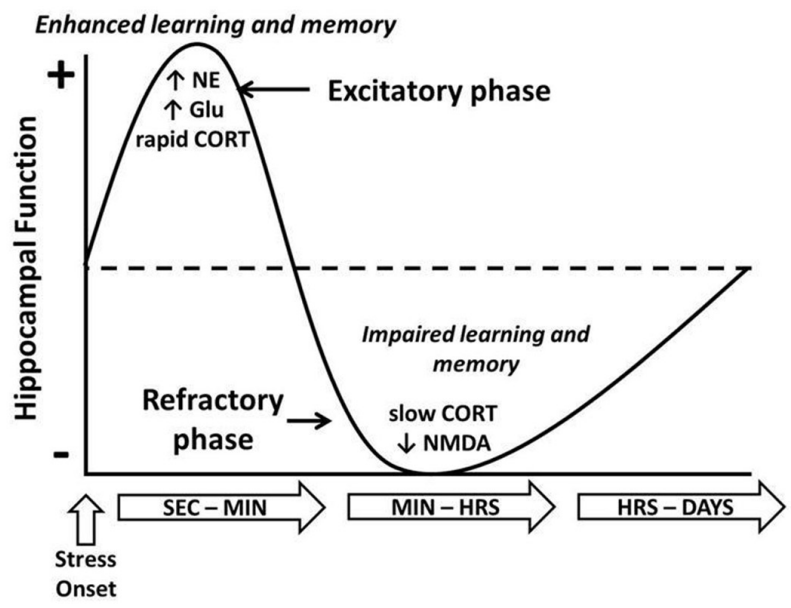

B
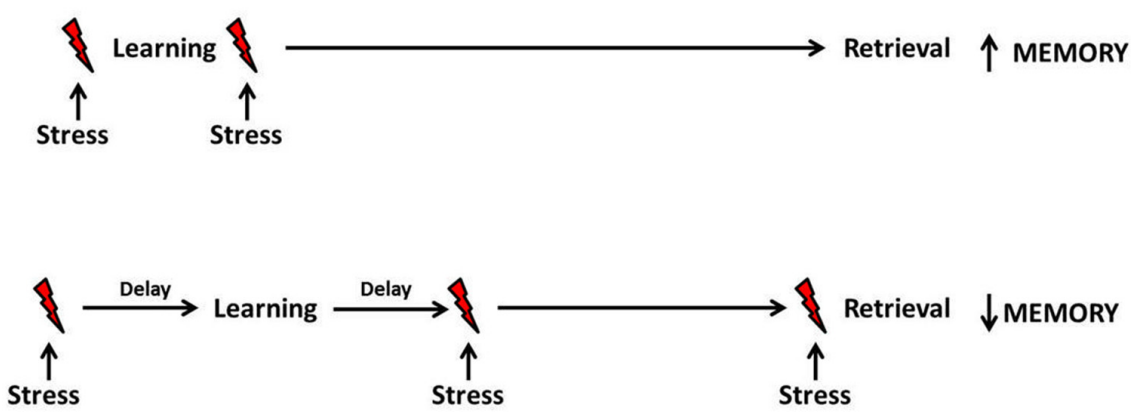

FIGURE 1| Temporal dynamics of acute stress effects on hippocampus-dependent learning and memory. Shortly following onset, stress induces a rapid increase in norepinephrine (NE), glutamate (Glu) and several other neurochemical substances (e.g., $\mathrm{CRH}$, acetylcholine, dopamine, etc.). Within a few minutes, corticosteroids (CORT) are also released and can exert rapid, non-genomic effects on cellular activity. Combined, this rapid stress-induced neurochemical activity results in an enhancement of hippocampal function, and learning that occurs around this time frame would be enhanced (A).
However, as time and/or the stressor continues, desensitization of glutamatergic NMDA receptors and delayed, gene-dependent corticosteroid activity results in an inhibition of hippocampal function, and learning that occurs around this time frame would be impaired. The bottom figure (B) illustrates these principles. When stress (indicated by the red lightning bolts) occurs in close temporal proximity to learning, long-term memory retrieval will be enhanced. When the stressor is temporally separated from the learning or occurs prior to retrieval, long-term memory will be impaired. closely in time. This enhancement results from shared neural circuits simultaneously forming memories for the learning event and stress event. As memory formation for a stress event is characterized by rapid psychobiological responses that allow for strong memory development, the resulting alteration of synaptic plasticity encodes information for both learning experiences. This enhanced consolidation for arousing experiences and learning events that occur in close proximity is adaptive in nature, allotting the highest priority of memory formation to events that code for information relevant to survival.

Alternatively, if a learning event occurs outside of a stress event context, or the events are temporally separated, encoding for this unrelated information would be significantly impaired as the neural circuits necessary for memory formation had already been previously saturated. As discussed, the hippocampus descends into a refractory period shortly following stress onset due to stress-induced synaptic saturation. Although the hippocampus does not display complete suppression, memory formation will be severely impaired. Much like the rapid facilitation of hippocampal LTP serves adaptive purposes, the refractory period also offers the organism benefits. The first benefit is a protection against increased glutamate exposure, which would eventually lead to neurotoxicity; second, the refractory period offers a short window in time in which the emotional memory experience can reduce corruption by subsequent learning; third, it allows for the consolidation of emotional information acquired in phase one (Diamond et al., 2007).

\section{Conclusion and Caveats}

Initial support for the temporal dynamics model of emotional memory processing came from preclinical work showing that a brief stressor applied immediately before learning could enhance 
long-term spatial memory in rats (Diamond et al., 2007). If the stressor was separated from the learning by a period of $30 \mathrm{~min}$, however, no memory enhancement was observed. More recently, investigators have extended the work to humans. This research has, for the most part, provided much needed support for the temporal dynamics model in people (Zoladz et al., 2011a, 2013, 2014b,c; Quaedflieg et al., 2013). However, some issues have arisen. One is that the sex of the organism appears to be influential in the types of effects that stressor timing has on learning and memory. Indeed, the temporal dynamics model was originally based on research performed in male, but not female, rodents. Thus, it is perhaps not surprising that work in humans has shown that females can respond very differently to the same stressor. As an example, Zoladz et al. (2013) reported that males, but not females, exhibited an impairment of longterm memory when exposed to a brief stressor $30 \mathrm{~min}$ prior to learning. These investigators also showed that stress immediately before learning reduced false memory production in males and females but enhanced true memory in females only (Zoladz et al., 2014c).

One factor that may underlie these observed sex-dependent effects is the modulatory role female sex hormones can exert on physiological mechanisms involved in memory formation. As many studies that have included female participants did not control for phase of the menstrual cycle, levels of estrogen and progesterone, or use of oral contraceptives, the possible interaction that may be occurring between female sex hormones and the time-dependent effects of stress-induced neurochemicals is not well understood. Further research investigating the modulatory role that female sex hormones may be playing in stress effects on learning and memory may offer much needed information as to how the timing of stress differentially influences learning and memory in males versus females.

An additional nuance that is important when considering the temporal dynamics model is the severity of the stressor. For severe stressors, the excitation phase of hippocampal function could be much more short-lived, or in the case of traumatic stressors, non-existent. For milder stressors, it is possible that the excitation phase could last longer. That the temporal dynamics

\section{References}

Abraham, I., Juhasz, G., Kekesi, K. A., and Kovacs, K. J. (1998). Corticosterone peak is responsible for stress-induced elevation of glutamate in the hippocampus. Stress 2, 171-181. doi: 10.3109/10253899809167281

Abraham, W. C., and Bear, M. F. (1996). Metaplasticity: the plasticity of synaptic plasticity. Trends Neurosci. 19, 126-130. doi: 10.1016/S0166-2236(96)80018-X

Akirav, I., and Richter-Levin, G. (1999). Biphasic modulation of hippocampal plasticity by behavioral stress and basolateral amygdala stimulation in the rat. J. Neurosci. 19, 10530-10535.

Akirav, I., and Richter-Levin, G. (2002). Mechanisms of amygdala modulation of hippocampal plasticity. J. Neurosci. 22, 9912-9921.

Andreano, J. M., and Cahill, L. (2006). Glucocorticoid release and memory consolidation in men and women. Psychol Sci. 17, 466-470. doi: 10.1111/j.14679280.2006.01729.x

Barnes, C. A., Jung, M. W., Mcnaughton, B. L., Korol, D. L., Andreasson, K., and Worley, P. F. (1994). LTP saturation and spatial learning disruption: effects of task variables and saturation levels. J. Neurosci. 14, 5793-5806. of stress-induced alterations of hippocampal function could vary from stressor to stressor could relate to individual differences in physiological responses to stress, perceptions of control in times of stress, and what constitutes a stressful event. Numerous studies have shown that some individuals respond strongly to laboratory stressors (defined as "Responders"), while others show little changes in SNS or HPA axis activity (defined as "NonResponders"). Moreover, it may be useful to consider what type of genetic variations across individuals could make them more or less susceptible to stress-induced changes in amygdala and hippocampal function. For instance, in a recent study, we showed that female carriers of the ADRA2B deletion variant (a genetic alteration that make the noradrenergic system more responsive to stress) were more susceptible to stress-induced enhancements of long-term memory (Zoladz et al., 2014b). If some genetic variants influence susceptibility to stress-induced enhancements of longterm memory, this could lend insight into who is more likely to form an intrusive, traumatic memory following extreme stress.

Finally, it is worth noting that the idea of stress inducing an amygdala-dependent biphasic effect on hippocampal function is largely dependent on electrophysiological work focusing more exclusively on the perforant pathway, which terminates in the dentate gyrus of the hippocampus. Other electrophysiological work has shown that corticosteorids can exert much different effects on different hippocampal subregions, such as CA1 and CA3 (Joels et al., 2009). Therefore, stress-induced amygdala activity, which biphasically influences dentate gyrus LTP, could affect other areas of the hippocampus in a different time-dependent manner.

Clearly, stress can exert differential effects on learning and memory depending on when it is administered and how long it lasts. Although the temporal dynamics notion may be an oversimplification of an overly complex area of research, it provides a useful guide for understanding how stress timedependently influences learning and its neurobiological basis. Future work is necessary to clarify how timing interacts with stress effects on memory and how sex and individual differences can influence these effects.

Bechara, A. (2005). Decision making, impulse control and loss of willpower to resist drugs: a neurocognitive perspective. Nat. Neurosci. 8, 1458-1463. doi: 10.1038/nn1584

Beckner, V. E., Tucker, D. M., Delville, Y., and Mohr, D. C. (2006). Stress facilitates consolidation of verbal memory for a film but does not affect retrieval. Behav. Neurosci. 120, 518-527. doi: 10.1037/0735-7044.120.3.518

Broadbent, N. J., Squire, L. R., and Clark, R. E. (2004). Spatial memory, recognition memory, and the hippocampus. Proc. Natl. Acad. Sci. U.S.A. 101, 14515-14520. doi: 10.1073/pnas.0406344101

Broadbent, N. J., Squire, L. R., and Clark, R. E. (2006). Reversible hippocampal lesions disrupt water maze performance during both recent and remote memory tests. Learn. Mem. 13, 187-191. doi: 10.1101/lm.134706

Brun, V. H., Ytterbo, K., Morris, R. G., Moser, M. B., and Moser, E. I. (2001). Retrograde amnesia for spatial memory induced by NMDA receptor-mediated long-term potentiation. J. Neurosci. 21, 356-362.

Buchanan, T. W., and Tranel, D. (2008). Stress and emotional memory retrieval: effects of sex and cortisol response. Neurobiol. Learn. Mem. 89, 134-141. doi: 10.1016/j.nlm.2007.07.003 
Buchanan, T. W., Tranel, D., and Adolphs, R. (2006). Impaired memory retrieval correlates with individual differences in cortisol response but not autonomic response. Learn. Mem. 13, 382-387. doi: 10.1101/lm.206306

Buss, C., Wolf, O. T., Witt, J., and Hellhammer, D. H. (2004). Autobiographic memory impairment following acute cortisol administration. Psychoneuroendocrinology 29, 1093-1096. doi: 10.1016/j.psyneuen.2003. 09.006

Cahill, L., Gorski, L., and Le, K. (2003). Enhanced human memory consolidation with post-learning stress: interaction with the degree of arousal at encoding. Learn. Mem. 10, 270-274. doi: 10.1101/lm.62403

Cahill, L., and McGaugh, J. L. (1998). Mechanisms of emotional arousal and lasting declarative memory. Trends Neurosci. 21, 294-299. doi: 10.1016/S01662236(97)01214-9

Campbell, A. M., Park, C. R., Zoladz, P. R., Muñoz, C., Fleshner, M., and Diamond, D. M. (2008). Pre-training administration of tianeptine, but not propranolol, protects hippocampus-dependent memory from being impaired by predator stress. Eur. Neuropsychopharmacol. 18, 87-98. doi: 10.1016/j.euroneuro.2007.04.004

Campbell, S., Marriott, M., Nahmias, C., and Macqueen, G. M. (2004). Lower hippocampal volume in patients suffering from depression: a meta-analysis. Am. J. Psychiatry 161, 598-607. doi: 10.1176/appi.ajp.161.4.598

Conboy, L., Tanrikut, C., Zoladz, P. R., Campbell, A. M., Park, C. R., Gabriel, C., et al. (2009). The antidepressant agomelatine blocks the adverse effects of stress on memory and enables spatial learning to rapidly increase neural cell adhesion molecule (NCAM) expression in the hippocampus of rats. Int. J. Neuropsychopharmacol. 12, 329-341. doi: 10.1017/S1461145708009255

Conrad, C. D., Jackson, J. L., Wieczorek, L., Baran, S. E., Harman, J. S., Wright R. L., et al. (2004). Acute stress impairs spatial memory in male but not female rats: influence of estrous cycle. Pharmacol. Biochem. Behav. 78, 569-579. doi: 10.1016/j.pbb.2004.04.025

Cole, A. J., Saffen, D. W., Baraban, J. M., and Worley, P. F. (1989). Rapid increase of an immediate early gene messenger RNA in hippocampal neurons by synaptic NMDA receptor activation. Nature 340, 474-476. doi: 10.1038/340474a0

Conrad, C. D., Lupien, S. J., and Mcewen, B. S. (1999). Support for a bimodal role for type II adrenal steroid receptors in spatial memory. Neurobiol. Learn. Mem. 72, 39-46. doi: 10.1006/nlme.1998.3898

de Kloet, E. R., Oitzl, M. S., and Joels, M. (1999). Stress and cognition: are corticosteroids good or bad guys? Trends Neurosci. 22, 422-426. doi: 10.1016/S0166-2236(99)01438-1

de Quervain, D. J., Roozendaal, B., and Mcgaugh, J. L. (1998). Stress and glucocorticoids impair retrieval of long-term spatial memory. Nature 394 787-790. doi: 10.1038/29542

Diamond, D. M., Bennett, M. C., Fleshner, M., and Rose, G. M. (1992). Inverted-U relationship between the level of peripheral corticosterone and the magnitude of hippocampal primed burst potentiation. Hippocampus 2, 421-430. doi: 10.1002/hipo.450020409

Diamond, D. M., Bennett, M. C., Stevens, K. E., Wilson, R. L., and Rose, G. M. (1990). Exposure to a novel environment interferes with the induction of hippocampal primed burst potentiation in the behaving rat. Psychobiology 18, 273-281.

Diamond, D. M., Campbell, A. M., Park, C. R., Halonen, J., and Zoladz, P. R. (2007). The temporal dynamics model of emotional memory processing: a synthesis on the neurobiological basis of stress-induced amnesia, flashbulb and traumatic memories, and the Yerkes-Dodson law. Neural Plast. 2007:60803. doi: $10.1155 / 2007 / 60803$

Diamond, D. M., Campbell, A. M., Park, C. R., Woodson, J. C., Conrad, C. D., Bachstetter, A. D., et al. (2006). Influence of predator stress on the consolidation versus retrieval of long-term spatial memory and hippocampal spinogenesis. Hippocampus 16, 571-576. doi: 10.1002/hipo.20188

Diamond, D. M., Fleshner, M., Ingersoll, N., and Rose, G. M. (1996). Psychological stress impairs spatial working memory: relevance to electrophysiological studies of hippocampal function. Behav. Neurosci. 110, 661-672. doi: 10.1037/07357044.110.4.661

Diamond, D. M., Park, C. R., Campbell, A. M., and Woodson, J. C. (2005). Competitive interactions between endogenous LTD and LTP in the hippocampus underlie the storage of emotional memories and stress-induced amnesia. Hippocampus 15, 1006-1025. doi: 10.1002/hipo. 20107
Diamond, D. M., Park, C. R., Heman, K. L., and Rose, G. M. (1999). Exposing rats to a predator impairs spatial working memory in the radial arm water maze. Hippocampus 9, 542-552. doi: 10.1002/(SICI)1098-1063(1999)9:5<542::AID$\mathrm{HIPO} 8>3.0 . \mathrm{CO} ; 2-\mathrm{N}$

Diamond, D. M., Park, C. R., and Woodson, J. C. (2004). Stress generates emotional memories and retrograde amnesia by inducing an endogenous form of hippocampal LTP. Hippocampus 14, 281-291. doi: 10.1002/hipo.10186

Diorio, D., Viau, V., and Meaney, M. J. (1993). The role of the medial prefrontal cortex (cingulate gyrus) in the regulation of hypothalamic-pituitary-adrenal responses to stress. J. Neurosci. 13, 3839-3847.

Duncko, R., Johnson, L., Merikangas, K., and Grillon, C. (2009). Working memory performance after acute exposure to the cold pressor stress in healthy volunteers. Neurobiol. Learn. Mem. 91, 377-381. doi: 10.1016/j.nlm.2009.01.006

Easterbrook, J. A. (1959). The effect of emotion on cue utilization and the organization of behavior. Psychol. Rev. 66, 183-201. doi: 10.1037/h0047707

Eichenbaum, H. (2004). Hippocampus: cognitive processes and neural representations that underlie declarative memory. Neuron 44, 109-120. doi: 10.1016/j.neuron.2004.08.028

Elzinga, B. M., Bakker, A., and Bremner, J. D. (2005). Stress-induced cortisol elevations are associated with impaired delayed, but not immediate recall. Psychiatry Res. 134, 211-223. doi: 10.1016/j.psychres.2004.11.007

Felmingham, K. L., Tran, T. P., Fong, W. C., and Bryant, R. A. (2012). Sex differences in emotional memory consolidation: the effect of stressinduced salivary alpha-amylase and cortisol. Biol. Psychol. 89, 539-544. doi: 10.1016/j.biopsycho.2011.12.006

Gooney, M., and Lynch, M. A. (2001). Long-term potentiation in the dentate gyrus of the rat hippocampus is accompanied by brain-derived neurotrophic factorinduced activation of TrkB. J. Neurochem. 77, 1198-1207. doi: 10.1046/j.14714159.2001.00334.x

Gunnar, M., and Quevedo, K. (2007). The neurobiology of stress and development. Annu. Rev. Psychol. 58, 145-173. doi: 10.1146/annurev.psych.58.110405. 085605

Hebb, D. O. (1949). The Organization of Behavior. New York, NY: Wiley.

Hossmann, K. A. (1999). The hypoxic brain. Insights from ischemia research. Adv. Exp. Med. Biol. 474, 155-169.

Huang, C. C., Yang, C. H., and Hsu, K. S. (2005). Do stress and long-term potentiation share the same molecular mechanisms? Mol. Neurobiol. 32, 223 235. doi: $10.1385 / \mathrm{MN}: 32: 3: 223$

Huang, Y. Y., Colino, A., Selig, D. K., and Malenka, R. C. (1992). The influence of prior synaptic activity on the induction of long-term potentiation. Science 255, 730-733. doi: 10.1126/science.1346729

Hui, I. R., Hui, G. K., Roozendaal, B., Mcgaugh, J. L., and Weinberger, N. M. (2006). Posttraining handling facilitates memory for auditory-cue fear conditioning in rats. Neurobiol. Learn. Mem. 86, 160-163. doi: 10.1016/j.nlm.2006.02.002

Jelicic, M., Geraerts, E., Merckelbach, H., and Guerrieri, R. (2004). Acute stress enhances memory for emotional words, but impairs memory for neutral words. Int. J. Neurosci. 114, 1343-1351. doi: 10.1080/00207450490476101

Joels, M. (2001). Corticosteroid actions in the hippocampus. J. Neuroendocrinol. 13, 657-669. doi: 10.1046/j.1365-2826.2001.00688.x

Joels, M., Fernandez, G., and Roozendaal, B. (2011). Stress and emotional memory: a matter of timing. Trends Cogn. Sci. 15, 280-288. doi: 10.1016/j.tics.2011. 04.004

Joels, M., and Krugers, H. J. (2007). LTP after stress: up or down? Neural Plast. 2007:93202. doi: 10.1155/2007/93202

Joels, M., Krugers, H. J., Lucassen, P. J., and Karst, H. (2009). Corticosteroid effects on cellular physiology of limbic cells. Brain Res. 1293, 91-100. doi: 10.1016/j.brainres.2009.03.036

Joels, M., Pu, Z., Wiegert, O., Oitzl, M. S., and Krugers, H. J. (2006). Learning under stress: how does it work? Trends Cogn. Sci. 10, 152-158. doi: 10.1016/j.tics.2006.02.002

Joels, M., Velzing, E., Nair, S., Verkuyl, J. M., and Karst, H. (2003). Acute stress increases calcium current amplitude in rat hippocampus: temporal changes in physiology and gene expression. Eur. J. Neurosci. 18, 1315-1324. doi: 10.1046/j.1460-9568.2003.02845.x

Joels, M., and Vreugdenhil, E. (1998). Corticosteroids in the brain. Cellular and molecular actions. Mol. Neurobiol. 17, 87-108. doi: 10.1007/BF02802026

Karst, H., Berger, S., Turiault, M., Tronche, F., Schutz, G., and Joels, M. (2005). Mineralocorticoid receptors are indispensable for nongenomic modulation of 
hippocampal glutamate transmission by corticosterone. Proc. Natl. Acad. Sci. U.S.A. 102, 19204-19207. doi: 10.1073/pnas.0507572102

Karst, H., and Joels, M. (2005). Corticosterone slowly enhances miniature excitatory postsynaptic current amplitude in mice CA1 hippocampal cells. J. Neurophysiol. 94, 3479-3486. doi: 10.1152/jn.00143.2005

Kaut, K. P., and Bunsey, M. D. (2001). The effects of lesions to the rat hippocampus or rhinal cortex on olfactory and spatial memory: retrograde and anterograde findings. Cogn. Affect. Behav. Neurosci. 1, 270-286. doi: 10.3758/CABN.1.3.270

Kensinger, E. A. (2004). Remembering emotional experiences: the contribution of valence and arousal. Rev. Neurosci. 15, 241-251. doi: 10.1515/REVNEURO.2004.15.4.241

Kim, J. J., Foy, M. R., and Thompson, R. F. (1996). Behavioral stress modifies hippocampal plasticity through N-methyl-D-aspartate receptor activation. Proc. Natl. Acad. Sci. U.S.A. 93, 4750-4753. doi: 10.1073/pnas.93.10.4750

Kim, J. J., Koo, J. W., Lee, H. J., and Han, J. S. (2005). Amygdalar inactivation blocks stress-induced impairments in hippocampal long-term potentiation and spatial memory. J. Neurosci. 25, 1532-1539. doi: 10.1523/JNEUROSCI.4623-04.2005

Kim, J. J., Lee, H. J., Han, J. S., and Packard, M. G. (2001). Amygdala is critical for stress-induced modulation of hippocampal long-term potentiation and learning. J. Neurosci. 21, 5222-5228.

Kim, J. J., and Yoon, K. S. (1998). Stress: metaplastic effects in the hippocampus. Trends Neurosci. 21, 505-509. doi: 10.1016/S0166-2236(98)01322-8

Kuhlmann, S., Kirschbaum, C., and Wolf, O. T. (2005a). Effects of oral cortisol treatment in healthy young women on memory retrieval of negative and neutral words. Neurobiol. Learn. Mem. 83, 158-162. doi: 10.1016/j.nlm.2004.09.001

Kuhlmann, S., Piel, M., and Wolf, O. T. (2005b). Impaired memory retrieval after psychosocial stress in healthy young men. J. Neurosci. 25, 2977-2982. doi: 10.1523/JNEUROSCI.5139-04.2005

Li, S., Weerda, R., Guenzel, F., Wolf, O. T., and Thiel, C. M. (2013). ADRA2B genotype modulates effects of acute psychosocial stress on emotional memory retrieval in healthy young men. Neurobiol. Learn. Mem. 103, 11-18. doi: 10.1016/j.nlm.2013.03.006

Lomo, T. (2003). The discovery of long-term potentiation. Philos. Trans. R. Soc. Lond. B Biol. Sci. 358, 617-620. doi: 10.1098/rstb.2002.1226

Lynch, M. A. (2004). Long-term potentiation and memory. Physiol. Rev. 84, 87-136. doi: 10.1152/physrev.00014.2003

Marmigere, F., Givalois, L., Rage, F., Arancibia, S., and Tapia-Arancibia, L. (2003). Rapid induction of BDNF expression in the hippocampus during immobilization stress challenge in adult rats. Hippocampus 13, 646-655. doi: 10.1002/hipo.10109

Marr, D. (1971). Simple memory: a theory for archicortex. Philos. Trans. R. Soc. Lond. B Biol. Sci. 262, 23-81. doi: 10.1098/rstb.1971.0078

McCullough, A. M., and Yonelinas, A. P. (2013). Cold-pressor stress after learning enhances familiarity-based recognition memory in men. Neurobiol. Learn. Mem. 106, 11-17. doi: 10.1016/j.nlm.2013.06.011

McEwen, B. S., and Chattarji, S. (2004). Molecular mechanisms of neuroplasticity and pharmacological implications: the example of tianeptine. Eur. Neuropsychopharmacol. 14(Suppl. 5), S497-S502. doi: 10.1016/j.euroneuro.2004.09.008

Mcewen, B. S., Macewen, B. S., and Weiss, J. M. (1970). The uptake and action of corticosterone: regional and subcellular studies on rat brain. Prog. Brain Res. 32, 200-212. doi: 10.1016/s0079-6123(08)61536-8

McEwen, B. S., Weiss, J. M., and Schwartz, L. S. (1968). Selective retention of corticosterone by limbic structures in rat brain. Nature 220, 911-912. doi: $10.1038 / 220911 \mathrm{a} 0$

McEwen, B. S., Weiss, J. M., and Schwartz, L. S. (1969). Uptake of corticosterone by rat brain and its concentration by certain limbic structures. Brain Res. 16, 227-241. doi: 10.1016/0006-8993(69)90096-1

McGaugh, J. L. (2004). The amygdala modulates the consolidation of memories of emotionally arousing experiences. Annu. Rev. Neurosci. 27, 1-28. doi: 10.1146/annurev.neuro.27.070203.144157

McNaughton, B. L., Barnes, C. A., Rao, G., Baldwin, J., and Rasmussen, M. (1986). Long-term enhancement of hippocampal synaptic transmission and the acquisition of spatial information. J. Neurosci. 6, 563-571.

Moser, E. I., and Moser, M. B. (1999). Is learning blocked by saturation of synaptic weights in the hippocampus? Neurosci. Biobehav. Rev. 23, 661-672. doi: $10.1016 /$ S0149-7634(98)00060-8
Moser, M. B., and Moser, E. I. (1998). Distributed encoding and retrieval of spatial memory in the hippocampus. J. Neurosci. 18, 7535-7542.

Muller, N. G., and Knight, R. T. (2006). The functional neuroanatomy of working memory: contributions of human brain lesion studies. Neuroscience 139, 51-58. doi: 10.1016/j.neuroscience.2005. 09.018

Nater, U. M., Moor, C., Okere, U., Stallkamp, R., Martin, M., Ehlert, U., et al. (2007). Performance on a declarative memory task is better in high than low cortisol responders to psychosocial stress. Psychoneuroendocrinology 32, 758-763. doi: 10.1016/j.psyneuen.2007.05.006

Nebel, K., Wiese, H., Stude, P., De Greiff, A., Diener, H. C., and Keidel, M. (2005). On the neural basis of focused and divided attention. Brain Res. Cogn. Brain Res. 25, 760-776. doi: 10.1016/j.cogbrainres.2005.09.011

Orchinik, M., Murray, T. F., and Moore, F. L. (1991). A corticosteroid receptor in neuronal membranes. Science 252, 1848-1851. doi: 10.1126/science.20 63198

Otnaess, M. K., Brun, V. H., Moser, M. B., and Moser, E. I. (1999). Pretraining prevents spatial learning impairment after saturation of hippocampal long-term potentiation. J. Neurosci. 19:RC49.

Park, C. R., Campbell, A. M., Woodson, J. C., Smith, T. P., Fleshner, M., and Diamond, D. M. (2006). Permissive influence of stress in the expression of a u-shaped relationship between serum corticosterone levels and spatial memory errors in rats. Dose Response 4, 55-74. doi: 10.2203/doseresponse.004.01.005.Park

Park, C. R., Fleshner, M., and Diamond, D. M. (2004). An NMDA antagonist can impair, protect or have no effect on memory depending on training parameters and stress at the time of retrieval. Soc. Neurosci. Abstr. 34, 776-722.

Park, C. R., Zoladz, P. R., Conrad, C. D., Fleshner, M., and Diamond, D. M. (2008). Acute predator stress impairs the consolidation and retrieval of hippocampusdependent memory in male and female rats. Learn. Mem. 15, 271-280. doi: 10.1101/lm.721108

Payne, J. D., Jackson, E. D., Hoscheidt, S., Ryan, L., Jacobs, W. J., and Nadel, L. (2007). Stress administered prior to encoding impairs neutral but enhances emotional long-term episodic memories. Learn. Mem. 14, 861-868. doi: 10.1101/lm.743507

Payne, J. D., Jackson, E. D., Ryan, L., Hoscheidt, S., Jacobs, J. W., and Nadel, L. (2006). The impact of stress on neutral and emotional aspects of episodic memory. Memory 14, 1-16. doi: 10.1080/09658210500139176

Payne, J. D., Nadel, L., Allen, J. J., Thomas, K. G., and Jacobs, W. J. (2002). The effects of experimentally induced stress on false recognition. Memory 10, 1-6. doi: 10.1080/09658210143000119

Platenik, J., Kuramoto, N., and Yoneda, Y. (2000). Molecular mechanisms associated with long-term consolidation of the NMDA signals. Life Sci. 67, 335-364. doi: 10.1016/S0024-3205(00)00632-9

Preuss, D., and Wolf, O. T. (2009). Post-learning psychosocial stress enhances consolidation of neutral stimuli. Neurobiol. Learn. Mem. 92, 318-326. doi: 10.1016/j.nlm.2009.03.009

Quaedflieg, C. W., Schwabe, L., Meyer, T., and Smeets, T. (2013). Time dependent effects of stress prior to encoding on event-related potentials and $24 \mathrm{~h}$ delayed retrieval. Psychoneuroendocrinology 38, 3057-3069. doi: 10.1016/j.psyneuen.2013.09.002

Roozendaal, B., Griffith, Q. K., Buranday, J., De Quervain, D. J., and Mcgaugh, J. L. (2003). The hippocampus mediates glucocorticoid-induced impairment of spatial memory retrieval: dependence on the basolateral amygdala. Proc. Natl. Acad. Sci. U.S.A. 100, 1328-1333. doi: 10.1073/pnas.0337480100

Roozendaal, B., Hahn, E. L., Nathan, S. V., De Quervain, D. J., and Mcgaugh, J. L. (2004). Glucocorticoid effects on memory retrieval require concurrent noradrenergic activity in the hippocampus and basolateral amygdala. J. Neurosci. 24, 8161-8169. doi: 10.1523/JNEUROSCI.2574-04.2004

Roozendaal, B., Mcewen, B. S., and Chattarji, S. (2009). Stress, memory and the amygdala. Nat. Rev. Neurosci. 10, 423-433. doi: 10.1038/nrn2651

Rowe, J. B., Owen, A. M., Johnsrude, I. S., and Passingham, R. E. (2001). Imaging the mental components of a planning task. Neuropsychologia 39, 315-327. doi: 10.1016/S0028-3932(00)00109-3

Sandi, C., Loscertales, M., and Guaza, C. (1997). Experience-dependent facilitating effect of corticosterone on spatial memory formation in the water maze. Eur. J. Neurosci. 9, 637-642. doi: 10.1111/j.1460-9568.1997.tb01412.x 
Sandi, C., Woodson, J. C., Haynes, V. F., Park, C. R., Touyarot, K., LopezFernandez, M.A., et al. (2005). Acute stress-induced impairment of spatial memory is associated with decreased expression of neural cell adhesion molecule in the hippocampus and prefrontal cortex. Biol. Psychiatry 57, 856864. doi: 10.1016/j.biopsych.2004.12.034

Sapolsky, R. M. (1996). Stress, Glucocorticoids, and damage to the nervous system: the current state of confusion. Stress 1, 1-19. doi: 10.3109/10253899609001092

Schoofs, D., and Wolf, O. T. (2009). Stress and memory retrieval in women: no strong impairing effect during the luteal phase. Behav. Neurosci. 123, 547-554. doi: $10.1037 / \mathrm{a} 0015625$

Schreiber, S. S., Tocco, G., Shors, T. J., and Thompson, R. F. (1991). Activation of immediate early genes after acute stress. Neuroreport 2, 17-20. doi: 10.1097/00001756-199101000-00004

Schwabe, L., Bohringer, A., Chatterjee, M., and Schachinger, H. (2008). Effects of pre-learning stress on memory for neutral, positive and negative words: different roles of cortisol and autonomic arousal. Neurobiol. Learn. Mem. 90, 44-53. doi: 10.1016/j.nlm.2008.02.002

Schwabe, L., Joels, M., Roozendaal, B., Wolf, O. T., and Oitzl, M. S. (2012). Stress effects on memory: an update and integration. Neurosci. Biobehav. Rev. 36, 1740-1749. doi: 10.1016/j.neubiorev.2011.07.002

Schwabe, L., Römer, S., Richter, S., Dockendorf, S., Bilak, B., and Schächinger, H. (2009). Stress effects on declarative memory retrieval are blocked by a betaadrenoceptor antagonist in humans. Psychoneuroendocrinology 34, 446-454. doi: 10.1016/j.psyneuen.2008.10.009

Schwabe, L., and Wolf, O. T. (2014). Timing matters: temporal dynamics of stress effects on memory retrieval. Cogn. Affect. Behav. Neurosci. 14, 1041-1048. doi: 10.3758/s13415-014-0256-0

Shors, T. J., and Matzel, L. D. (1997). Long-term potentiation: what's learning got to do with it? Behav. Brain Sci. 20, 597-614. doi: 10.1017/s0140525x97001593

Shors, T. J., and Thompson, R. F. (1992). Acute stress impairs (or induces) synaptic long-term potentiation (LTP) but does not affect paired-pulse facilitation in the stratum radiatum of rat hippocampus. Synapse 11, 262-265. doi: 10.1002/syn.890110311

Smeets, T. (2011). Acute stress impairs memory retrieval independent of time of day. Psychoneuroendocrinology 36, 495-501. doi: 10.1016/j.psyneuen.2010. 08.001

Smeets, T., Otgaar, H., Candel, I., and Wolf, O. T. (2008). True or false? Memory is differentially affected by stress-induced cortisol elevations and sympathetic activity at consolidation and retrieval. Psychoneuroendocrinology 33, 13781386. doi: 10.1016/j.psyneuen.2008.07.009

Smeets, T., Wolf, O. T., Giesbrecht, T., Sijstermans, K., Telgen, S., and Joëls, M. (2009). Stress selectively and lastingly promotes learning of context-related high arousing information. Psychoneuroendocrinology 34, 1152-1161. doi: 10.1016/j.psyneuen.2009.03.001

Squire, L. R., Stark, C. E., and Clark, R. E. (2004). The medial temporal lobe. Annu. Rev. Neurosci. 27, 279-306. doi: 10.1146/annurev.neuro.27.070203.144130

Takahashi, T., Kimoto, T., Tanabe, N., Hattori, T. A., Yasumatsu, N., and Kawato, S. (2002). Corticosterone acutely prolonged N-methyl-d-aspartate receptor-mediated $\mathrm{Ca}^{2+}$ elevation in cultured rat hippocampal neurons. J. Neurochem. 83, 1441-1451. doi: 10.1046/j.1471-4159.2002.01251.x

Tocco, G., Maren, S., Shors, T. J., Baudry, M., and Thompson, R. F. (1992). Long-term potentiation is associated with increased [3H]AMPA binding in rat hippocampus. Brain Res. 573, 228-234. doi: 10.1016/0006-8993(92)90767-4

Tocco, G., Shors, T. J., Baudry, M., and Thompson, R. F. (1991). Selective increase of AMPA binding to the AMPA/quisqualate receptor in the hippocampus in response to acute stress. Brain Res. 559, 168-171. doi: 10.1016/00068993(91)90302-C
Tollenaar, M. S., Elzinga, B. M., Spinhoven, P., and Everaerd, W. (2008). Long-term outcomes of memory retrieval under stress. Behav. Neurosci. 122, 697-703. doi: 10.1037/0735-7044.122.3.697

Venero, C., and Borrell, J. (1999). Rapid glucocorticoid effects on excitatory amino acid levels in the hippocampus: a microdialysis study in freely moving rats. Eur. J. Neurosci. 11, 2465-2473. doi: 10.1046/j.1460-9568.1999.00668.x

Woodson, J. C., Macintosh, D., Fleshner, M., and Diamond, D. M. (2003). Emotion-induced amnesia in rats: working memory-specific impairment, corticosterone-memory correlation, and fear versus arousal effects on memory. Learn. Mem. 10, 326-336. doi: 10.1101/lm.62903

Wolf, O. T. (2009). Stress and memory in humans: twelve years of progress? Brain Res. 1293, 142-154. doi: 10.1016/j.brainres.2009.04.013

Zoladz, P. R., Clark, B., Warnecke, A., Smith, L., Tabar, J., and Talbot, J. N. (2011a). Pre-learning stress differentially affects long-term memory for emotional words, depending on temporal proximity to the learning experience. Physiol. Behav. 103, 467-476. doi: 10.1016/j.physbeh.2011.01.016

Zoladz, P. R., Park, C. R., and Diamond, D. M. (2011b). "Neurobiological basis of the complex effects of stress on memory and synaptic plasticity," in The Handbook of Stress: Neuropsychological Effects on the Brain, ed. C. D. Conrad (Oxford: Wiley-Blackwell), 157-178. doi: 10.1002/9781118083222.ch8

Zoladz, P. R., and Diamond, D. M. (2013). Current status on behavioral and biological markers of PTSD: a search for clarity in a conflicting literature. Neurosci. Biobehav. Rev. 37, 860-895. doi: 10.1016/j.neubiorev.2013. 03.024

Zoladz, P. R., Kalchik, A. E., Cadle, C. E., and Lyle, S. M. (2014a). “Amygdalainduced modulation of cognitive brain structures underlies stress-induced alterations of learning and memory: importance of stressor timing and sex differences," in Horizons in Neuroscience Research, eds A. Costa and E. Villalba (Hauppauge, NY: Nova Science Publishers), 1-40.

Zoladz, P. R., Kalchik, A. E., Hoffman, M. M., Aufdenkampe, R. L., Lyle, S. M., Peters, D. M., et al. (2014b). ADRA2B deletion variant selectively predicts stress-induced enhancement of long-term memory in females. Psychoneuroendocrinology 48, 111-122. doi: 10.1016/j.psyneuen.2014. 06.012

Zoladz, P. R., Peters, D. M., Kalchik, A. E., Hoffman, M. M., Aufdenkampe, R. L., Woelke, S. A., et al. (2014c). Brief, pre-learning stress reduces false memory production and enhances true memory selectively in females. Physiol. Behav. 128, 270-276. doi: 10.1016/j.physbeh.2014.02.028

Zoladz, P. R., Warnecke, A. J., Woelke, S. A., Burke, H. M., Frigo, R. M., Pisansky, J. M., et al. (2013). Pre-learning stress that is temporally removed from acquisition exerts sex-specific effects on long-term memory. Neurobiol. Learn. Mem. 100, 77-87. doi: 10.1016/j.nlm.2012.12.012

Zoladz, P. R., Woodson, J. C., Haynes, V. F., and Diamond, D. M. (2010). Activation of a remote (1-year old) emotional memory interferes with the retrieval of a newly formed hippocampus-dependent memory in rats. Stress 13, 36-52. doi: $10.3109 / 10253890902853123$

Conflict of Interest Statement: The authors declare that the research was conducted in the absence of any commercial or financial relationships that could be construed as a potential conflict of interest.

Copyright (c) 2015 Cadle and Zoladz. This is an open-access article distributed under the terms of the Creative Commons Attribution License (CC BY). The use, distribution or reproduction in other forums is permitted, provided the original author(s) or licensor are credited and that the original publication in this journal is cited, in accordance with accepted academic practice. No use, distribution or reproduction is permitted which does not comply with these terms. 